\title{
Influence of Ore Reducibility on Reaction Behavior of Ore Bed Mixed with Coal Composite Iron Ore Hot Briquettes
}

\author{
Hironori SUZUKI, ${ }^{1)}$ Hiroyuki MIZOGUCHI ${ }^{1)}$ and Shoji HAYASHI ${ }^{2)}$ \\ 1) Graduate Student, Graduate School of Materials Engineering, Nagoya Institute of Technology, Gokiso-cho, Showa-ku, \\ Nagoya, 466-8555 Japan. \\ 2) Graduate School of Materials Engineering, Nagoya Institute of Technology, Gokiso-cho, Showa-ku, Nagoya, $466-8555$ Japan.
}

(Received on January 28, 2011; accepted on May 9, 2011)

\begin{abstract}
Reaction behavior of a packed bed consisting of reagent pellets $A$ or iron ore mini pellets $B$ and coal composite iron ore hot briquettes was examined under the blast furnace simulated conditions until $1200^{\circ} \mathrm{C}$

As a result, it was found that reducibility of the mixed bed is governed by reducibility of pellets, whereas gasification of briquettes in the mixed bed is hardly governed by it. However, promotion effects for reduction and gasification of the mixed beds were recognized for both pellets around $1050^{\circ} \mathrm{C}$, where abnormal swelling of the easier reduced pellet $A$ occurred remarkably with fine fibrous irons, showing a noticeable pressure drop through the bed. It was suggested that this swelling would be caused by gaseous sulfur derived from coal char in the briquettes.

The mixed beds provided larger final shrinkage of the beds than the individual beds probably due to increment of the coupling reactions between reduction and gasification.

It was concluded that reducibility of the pellet could influence not only the reducibility of the mixed bed but also the overall reaction behavior such as gas permeability and softening.
\end{abstract}

KEY WORDS: mixed packed bed; coal composite iron ore hot briquette; ore reducibility; blast furnace simulated reaction behavior.

\section{Introduction}

In order to reduce $\mathrm{CO}_{2}$ emission from ironmaking process, more efficient operation in blast furnace is required. The new burdens such as partial reduced agglomerates, ${ }^{1,2}$ carbon composite iron ore agglomerate ${ }^{3)}$ and iron coke ${ }^{4)}$ have been investigated.

In these burdens, coal composite iron ore hot briquette is agglomerated by utilizing thermal plasticity of coal without binder and expected that it lowers reduction reaction temperature and reaction rate increases by high degree adjoining between coal and iron ore particles. ${ }^{5)}$ Therefore, it is reported that the starting temperature of reaction was lowered when small amounts of briquettes was mixed into the packed ore bed. ${ }^{6}$

On these backgrounds, we have investigated influence of several experimental conditions such as mixing ratio of briquette, gas flow rate and thermal reserve zone temperature on reaction behavior of the briquettes mixed packed bed. ${ }^{7-9)}$

In this paper, we will describe the influence of ore reducibility on blast furnace simulated reaction behavior of the packed ore bed mixed with coal composite iron ore hot briquettes.

\section{Experimental Procedure}

\subsection{Sample}

Samples consist of the mixture of iron ore mini pellets and small crushed coal composite hot briquette particles (1.7-2.8 $\mathrm{mm}$ size on both pellets and briquettes). Two types of ore pellets, $5 \mathrm{~mol} \% \mathrm{CaO}-\mathrm{Fe}_{2} \mathrm{O}_{3}$ pellet (pellet A) and iron ore mini pellet (pellet B) are prepared. 8 types of samples are used for mixing ratios of briquettes (Mark; B, $0 \% \mathrm{~B}$, $20 \% \mathrm{~B}, 50 \% \mathrm{~B}, 100 \% \mathrm{~B})$ and types of pellets. Chemical compositions of these samples as a result of calculation are shown in Table 1.

Table 1. Chemical composition of sample (mass\%).

\begin{tabular}{|c|c|c|c|c|c|c|c|c|c|}
\hline \multirow{2}{*}{$\begin{array}{l}\text { Mixed ratio } \\
\text { in sample }\end{array}$} & \multirow{2}{*}{ T.Fe } & \multirow{2}{*}{$\Sigma \mathrm{O}$} & \multicolumn{4}{|c|}{ Gangue } & \multirow{2}{*}{$\mathrm{C}$} & \multirow{2}{*}{$\mathrm{H}, \mathrm{N}, \mathrm{S}, \mathrm{O}$} & \multirow{2}{*}{ Ash } \\
\hline & & & $\mathrm{Al}_{2} \mathrm{O}_{3}$ & $\mathrm{SiO}_{2}$ & $\mathrm{CaO}$ & $\mathrm{MgO}$ & & & \\
\hline PelletA- $0 \% \mathrm{~B}$ & 68.67 & 29.51 & 0 & 0 & 1.82 & 0 & 0 & 0 & 0 \\
\hline PelletA-20\%B & 65.79 & 28.27 & 0.06 & 0.29 & 1.46 & 0 & 3.12 & 0.64 & 0.38 \\
\hline PelletA-50\%B & 61.46 & 26.41 & 0.14 & 0.72 & 0.93 & 0 & 7.79 & 1.59 & 0.94 \\
\hline PelletB- $0 \% \mathrm{~B}$ & 66.23 & 28.46 & 0.75 & 1.56 & 1.57 & 0.85 & 0 & 0 & 0 \\
\hline PelletB-20\%B & 63.83 & 27.43 & 0.66 & 1.53 & 1.27 & 0.68 & 3.12 & 0.64 & 0.38 \\
\hline PelletB- $50 \%$ B & 60.23 & 25.88 & 0.52 & 1.50 & 0.81 & 0.43 & 7.79 & 1.59 & 0.94 \\
\hline $100 \% \mathrm{~B}$ & 54.24 & 23.31 & 0.28 & 1.43 & 0.05 & 0 & 15.58 & 3.19 & 1.88 \\
\hline
\end{tabular}




\subsubsection{Method of Preparing Pellets}

Method of preparing for pellet $\mathrm{A}$ is described below. First, pellets which are pelletized with reagent $\mathrm{Fe}_{2} \mathrm{O}_{3}$ and pure water are roasted in air at $1300^{\circ} \mathrm{C}$ for $1 \mathrm{hr}$. These pellets are crushed into $53 \mu \mathrm{m}$ less or equal fines. Next, the mixture of these $\mathrm{Fe}_{2} \mathrm{O}_{3}$ fines and reagent $\mathrm{CaCO}_{3}$ $\left(\mathrm{Fe}_{2} \mathrm{O}_{3}: \mathrm{CaCO}_{3}=98.185: 1.815\right.$ (mass\%)) is pelletized using a pan-type granulating machine with adding appropriate pure water as binder. These pellets are roasted in air at $1100^{\circ} \mathrm{C}$ for $1 \mathrm{hr}$ and finally screened between 1.7 and $2.8 \mathrm{~mm}$.

\subsubsection{Method of Preparing Briquette}

Coal (Rio Tinto, $-45 \mu \mathrm{m}$ dia.) and iron ore (Samarco, $45-$ $75 \mu \mathrm{m}$ dia.) are used as raw materials to produce briquettes. These chemical compositions are shown in Tables $\mathbf{2}$ and $\mathbf{3}$. Mixture of coal and iron ore (mixing molar ratio: $\mathrm{C} / \mathrm{O}=1$ ) is set in a pressing machine and heated until max fluidity temperature of coal $426^{\circ} \mathrm{C}$ (maximum fluidity $115 \mathrm{ddpm}$ ) for 20 min under applying load 2 ton in $\mathrm{N}_{2}$ atmosphere. After reaching to the temperature, 4 ton load is applied to the mixture for $2 \mathrm{~min}$ and cooled down to room temperature. These obtained briquettes (diameter: $15 \mathrm{~mm}$, height: $9.5 \mathrm{~mm}$ ) are crushed and screened between 1.7 and $2.8 \mathrm{~mm}$.

\subsection{Blast Furnace Simulated Reaction Experiment}

Experimental reaction apparatus is shown in Fig. 1. Graphite supporting tube and crucible (inner diameter: $18 \mathrm{~mm}$, height: $75 \mathrm{~mm}$ ) are covered with alumina water slurry to prevent reactions from reaction gas and sample. A sample is filled in the graphite crucible after arranging small alumina balls ( $3 \mathrm{~mm}$ dia.) in the lower part to adjust a bed

Table 2. Chemical composition of coal (mass\%).

\begin{tabular}{ccccccc}
\hline & $\mathrm{C}$ & $\mathrm{H}$ & $\mathrm{N}$ & $\mathrm{S}$ & $\mathrm{O}$ & Ash \\
\hline Rio Tinto & 76.2 & 5.05 & 2.3 & 0.55 & 7.7 & 8.2 \\
\hline
\end{tabular}

Table 3. Chemical composition of iron ore (mass $\%$ ).

\begin{tabular}{ccccccccc}
\hline & T.Fe & $\mathrm{FeO}$ & $\mathrm{Al}_{2} \mathrm{O}_{3}$ & $\mathrm{SiO}_{2}$ & $\mathrm{CaO}$ & $\mathrm{S}$ & $\mathrm{P}$ & C.W \\
\hline Samarco & 66.74 & 0.68 & 0.35 & 1.76 & 0.06 & 0.005 & 0.051 & 2.35 \\
\hline
\end{tabular}

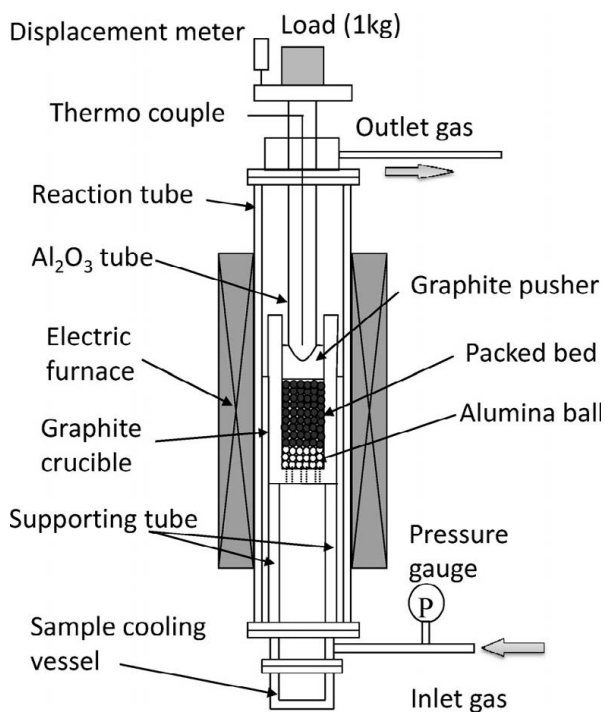

Fig. 1. Blast furnace simulated reactor. height of $32 \mathrm{~mm}$. After putting the graphite pusher with gas holes and applying $1 \mathrm{~kg}$ load, reaction test is performed from room temperature to $1200^{\circ} \mathrm{C}$ under the heat pattern and gas content simulated on the basis of real blast furnace as shown in Fig. 2 (thermal reserve zone temperature: $900^{\circ} \mathrm{C}$, gas flow rate: $\left.1 \mathrm{NL} / \mathrm{min}\right) .{ }^{10)}$

Shrinkage of sample and pressure drop through a packed bed are measured automatically during the reaction. Reaction tests were performed until predetermined times $\left(87.5 \min \left(750^{\circ} \mathrm{C}\right), 99 \min \left(900^{\circ} \mathrm{C}\right), 129 \min \left(900^{\circ} \mathrm{C}\right)\right.$, $\left.159 \min \left(1050^{\circ} \mathrm{C}\right), 189 \min \left(1200^{\circ} \mathrm{C}\right)\right)$ and then the samples were cooled in $\mathrm{N}_{2}$ stream to protect them from oxidization. For these partial reacted samples, weight loss, carbon and sulfur contents and observation in cross section by optical microscope were performed.

\section{Experimental Results and Discussion}

\subsection{Reduction and Gasification Degrees}

3.1.1. Computation of Reduction and Gasification Degrees

Reduction and gasification degrees of a packed bed can be calculated by Eqs. (1)-(5) with both measured weight loss and carbon content after partial reaction.

$$
\begin{gathered}
W_{O}+W_{C}+W_{H, N, S, O}=W \ldots \\
W_{C}=\% C_{0}+\% C\left(\frac{W}{100}-1\right) \\
W_{C}=A \times W_{H, N, S, O} \\
D_{r}=\frac{W_{O}}{\% O_{0}} \times 100 \ldots \ldots \\
D_{g}=100-\frac{\% C}{\% C_{0}}(100-W)
\end{gathered}
$$

Here, $W_{0}$ : weight loss of reduced oxygen $(\%), W_{C}$ : weight loss of carbon (\%), $W_{H, N, S, O}$ : weight loss of $H, N, S$ and $O$ in carbon material $(\%), W$ : weight loss of sample $(\%), \% C_{0}$ : carbon content before reaction $(\%), \% C$ : carbon content after reaction $(\%), A$ : constant from Table $2, D_{r}$ : reduction degree $(\%), \% O_{0}$ : reduced oxygen content before reaction $(\%), D_{g}$ : gasification degree $(\%)$.

\subsubsection{Influence of Pellet Types}

Reduction degrees of mixed packed beds with reaction time are shown in Fig. 3. Reduction of pellet A proceed

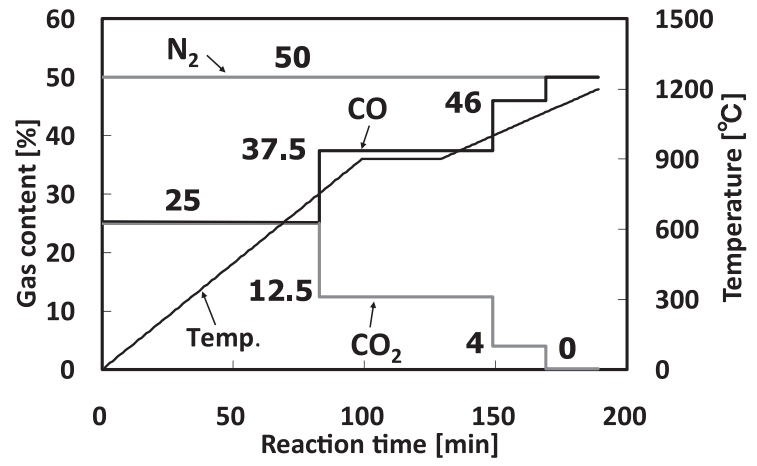

Fig. 2. Experimental conditions (Flow gas and heat pattern). 


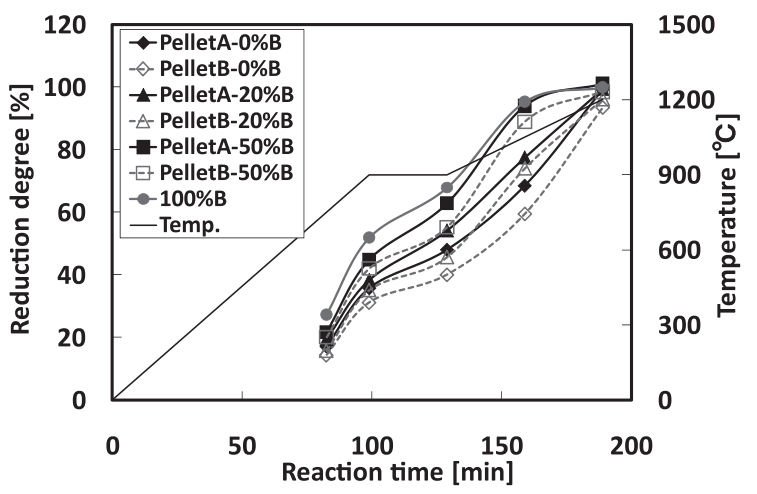

Fig. 3. Reduction degree with reaction time.

more than pellet $\mathrm{B}$ during whole periods for $0 \% \mathrm{~B}$ samples consisting of only pellets. Furthermore, $20 \% \mathrm{~B}$ and $50 \% \mathrm{~B}$ samples including pellet A proceed more than that including pellet $\mathrm{B}$ in same manner. Accordingly, it was found that reducibility of a mixed packed bed is governed by reducibility of pellets. As a result for both pellets, the higher the mixing ratio of briquettes is, the faster the reduction of a packed bed is, showing that reduction degrees for their beds on both pellets reached finally to nearly $100 \%$.

Next, reaction promotion effect induced by mixing briquettes is evaluated by using the predicted reduction degree. Predicted weight loss and carbon content can be estimated by Eqs. (6) and (7).

$$
\begin{gathered}
W_{x \% B}=W_{0 \% B} \times \frac{100-x}{100}+W_{100 \% B} \times \frac{x}{100} \ldots . . \\
\% C_{x \% B}=\% C_{0 \% B} \times \frac{100-x}{100}+\% C_{100 \% B} \times \frac{x}{100}
\end{gathered}
$$

Here, $W_{x \% B}$ : predicted weight loss on the sample including $x \%$ briquettes $(\%), W_{0 \% B}$ : weight loss on $0 \% B$ sample $(\%)$, $\mathrm{W}_{100 \% \mathrm{~B}}$ : weight loss on $100 \% B$ sample $(\%), \% C_{x \% B}$ : predicted carbon content on the sample including $x \%$ briquettes $(\%), \% C_{0 \% B}$ : carbon content on $0 \% B$ sample after reaction $(\%),{ }_{0} C_{100 \% B}$ : carbon content on $100 \% B$ sample after reaction $(\%)$.

By substituting the values obtained by Eqs. (6) and (7) into Eqs. (1)-(4), we can obtain predicted reduction degrees. Predicted values are calculated assuming that the same quantity of pellets and briquettes reacted individually. Differences between measured and predicted reduction degrees obtained for partial reaction at each temperature and time are shown in Fig. 4, where it is clear that promotion of reduction is recognized on the both pellets and the promotion degrees are different for reaction temperatures.

At $900^{\circ} \mathrm{C}(129 \mathrm{~min})$, the promotion effect of the samples including pellet $\mathrm{A}$ is larger than that including pellet $\mathrm{B}$, giving less than $5 \%$. This is probably because $\mathrm{CO}$ generated by carbon solution loss reaction is utilized efficiently to the indirect reduction of pellet $\mathrm{A}$ than that of pellet $\mathrm{B}$ due to high reducibility in lower temperatures for pellet A. Around $1050{ }^{\circ} \mathrm{C}$, the promotion effect of $50 \% \mathrm{~B}$ samples for both pellets were recognized nearly $10 \%$.

Then, gasification degrees of mixed packed beds calculated by Eq. (5) with reaction time are shown in Fig. 5. Gasification process showed the same tendency on both pellets.

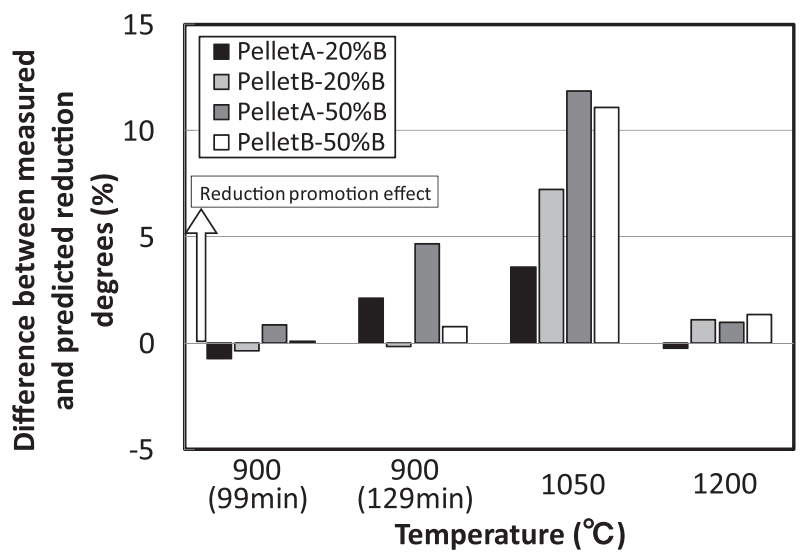

Fig. 4. Difference between measured and predicted reduction degrees for each temperature.

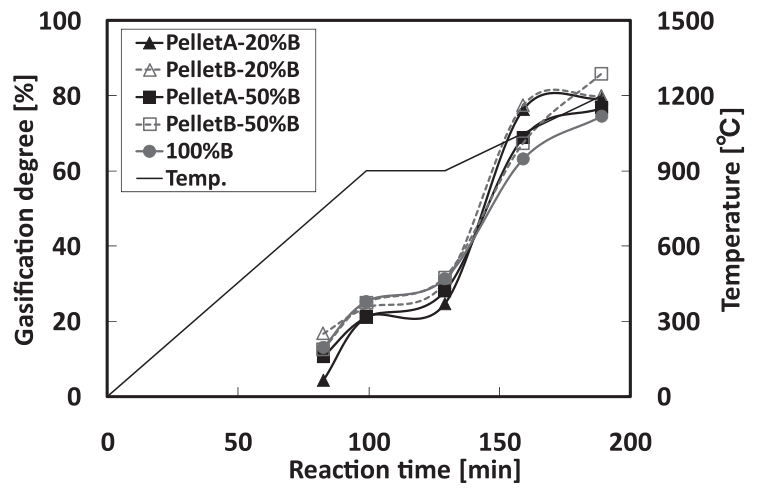

Fig. 5. Gasification degree with reaction time.

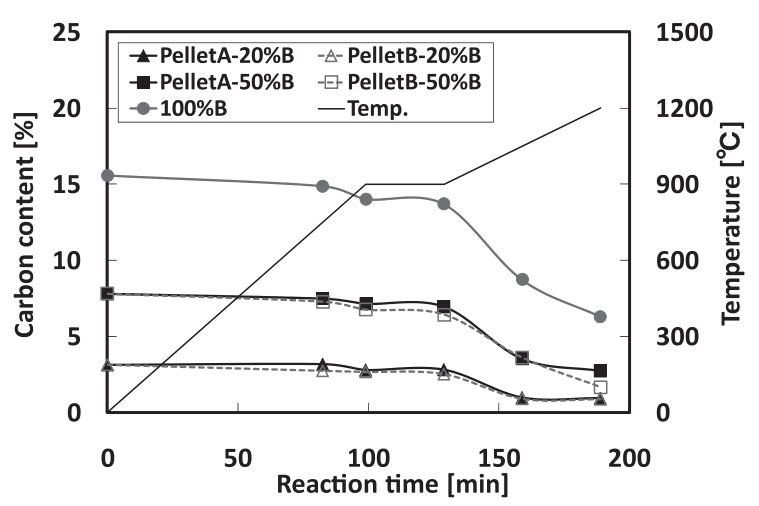

Fig. 6. Carbon content with reaction time.

Carbon contents with reaction time is also shown in Fig. 6. Carbon contents showed similarly the same tendency on both pellets. As a result, gasification behavior of briquettes in the packed bed is hardly influenced by the reducibility of pellets, showing that gasification degrees for their beds on both pellets reached finally to nearly $80 \%$.

Difference between measured and predicted gasification degrees is also estimated to evaluate the gasification promotion effect, as shown in Fig. 7. As a result, at $900^{\circ} \mathrm{C}(99 \mathrm{~min}$ and $129 \mathrm{~min}$ ), the promotion effect on samples including pellet $\mathrm{B}$ is larger than that on those including pellet A, giving nearly $5 \%$. Around $1050^{\circ} \mathrm{C}$, the promotion effects of $20 \%$ B samples for both pellets were recognized nearly $20 \%$.

Particularly, around $1050^{\circ} \mathrm{C}$, promotion effects for reduction and gasification were most remarkable as shown 


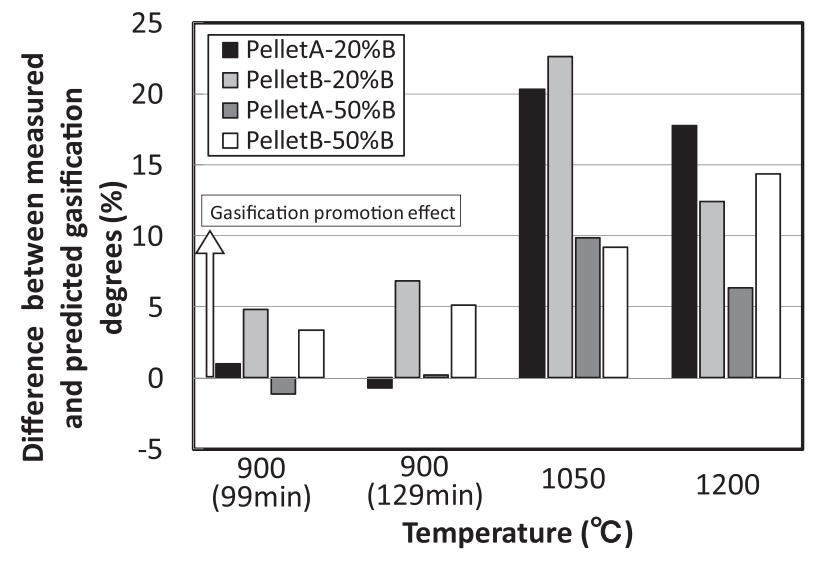

Fig. 7. Difference between measured and predicted gasification degrees for each temperature.
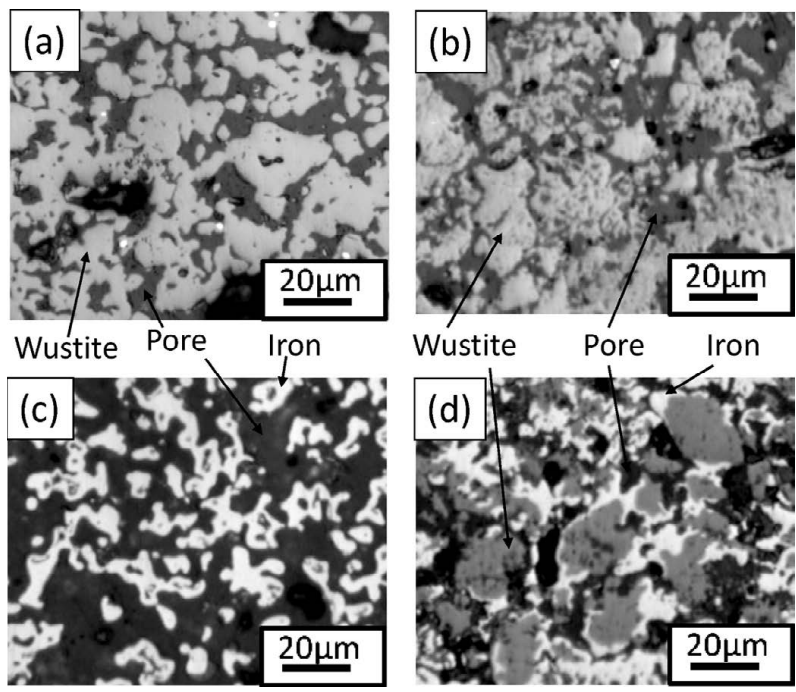

Fig. 8. Microstructures of cross section of pellets in packed beds after reaction $\left(0 \% \mathrm{~B}, 1050^{\circ} \mathrm{C}\right)$ : (a), (b) In upper part, (c), (d) In lower part, (a), (c) Pellet A, (b), (d) Pellet B.

in Figs. 4 and 7, probably because of the mutual acceleration of both reactions between the reduction of iron oxides in pellets (8) and the gasification of char coal in briquettes (9).

$$
\begin{array}{r}
F e_{m} O_{n}(s)+C O(g)=\mathrm{Fe}_{m} \mathrm{O}_{n-1}(s)+\mathrm{CO}_{2}(g) \\
\mathrm{C}(s)+\mathrm{CO}_{2}(g)=2 \mathrm{CO}(\mathrm{g})
\end{array}
$$

\subsubsection{Reduction Behavior of Pellets in Packed Beds}

Microstructures in cross section (pellets in the upper and lower parts of a packed bed) for $0 \% \mathrm{~B}, 1050^{\circ} \mathrm{C}$ obtained by optical microscope are shown in Fig. 8. Reduced iron grains are observed in the lower part of the both packed beds, whereas wustite grains are mainly observed in the upper part of the packed beds. Therefore, $\mathrm{CO}_{2}$ contents in the upper parts would be higher than in the lower parts.

Next, microstructures in the similar parts for $50 \% \mathrm{~B}$, $1050^{\circ} \mathrm{C}$, at which high reduction promotion effect were relatively observed in Fig. 4, are shown in Fig. 9. Reduction is mostly finished in the upper part for pellet $\mathrm{A}-50 \% \mathrm{~B}$, whereas wustite grains are still observed in the both parts for pellet $\mathrm{B}-50 \% \mathrm{~B}$. As a result, it is clear that reduction rates for pellet $\mathrm{B}$ are smaller than those for pellet $\mathrm{A}$. However, for
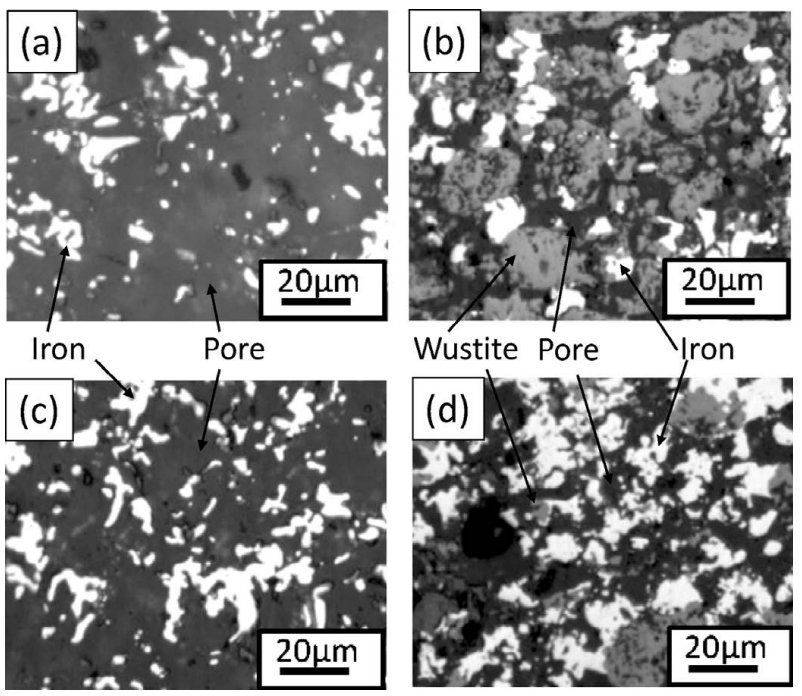

Fig. 9. Microstructures of cross section of pellets in packed beds after reaction $\left(50 \% \mathrm{~B}, 1050^{\circ} \mathrm{C}\right)$ : (a), (b) In upper part, (c), (d) In lower part, (a), (c) Pellet A, (b), (d) Pellet B.

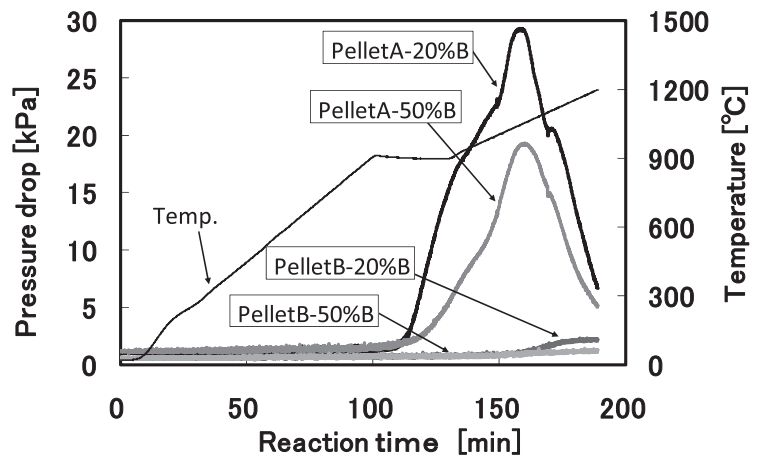

Fig. 10. Pressure drop through packed bed with reaction time.

both pellets, the amount of reduced irons in upper part for $50 \% \mathrm{~B}$ is more than for $0 \% \mathrm{~B}$. As a consequence, it is found that mixing briquettes promote reduction in the upper part, similarly for $20 \% \mathrm{~B}, 1050^{\circ} \mathrm{C}$.

\subsection{Pressure Drop through a Packed Bed}

Pressure drops through the packed bed with reaction time are shown in Fig. 10. On pellet A-20\%B and $-50 \%$ B, pressure drops increase from around $110 \mathrm{~min}$, reach maximum around $160 \mathrm{~min}$ and decrease toward $190 \mathrm{~min}$. In contrast, on pellet $\mathrm{B}-20 \% \mathrm{~B}$ and $-50 \% \mathrm{~B}$, their increment are not almost observed. These increase of pressure drops on pellet A- $20 \% \mathrm{~B}$ and $-50 \% \mathrm{~B}$ is probably caused by swelling of pellets. (ref. next section)

\subsubsection{Swelling Behavior of Pellets}

To investigate swelling behavior of pellets, reaction tests by a thermobalance were performed under the same heat pattern, gas content and flow rate conditions until $1050^{\circ} \mathrm{C}$ using pellet A-20\%B and pellet B-20\%B. A sample in a basket weighs 2 gram. Macro photographs of samples before and after test are shown in Fig. 11. From these photographs, abnormal swelling occurred on pellet $\mathrm{A}$, the diameter of which was nearly three times as large as before test. Contrary, such swelling like pellet A was not almost observed on pellet $B$. 

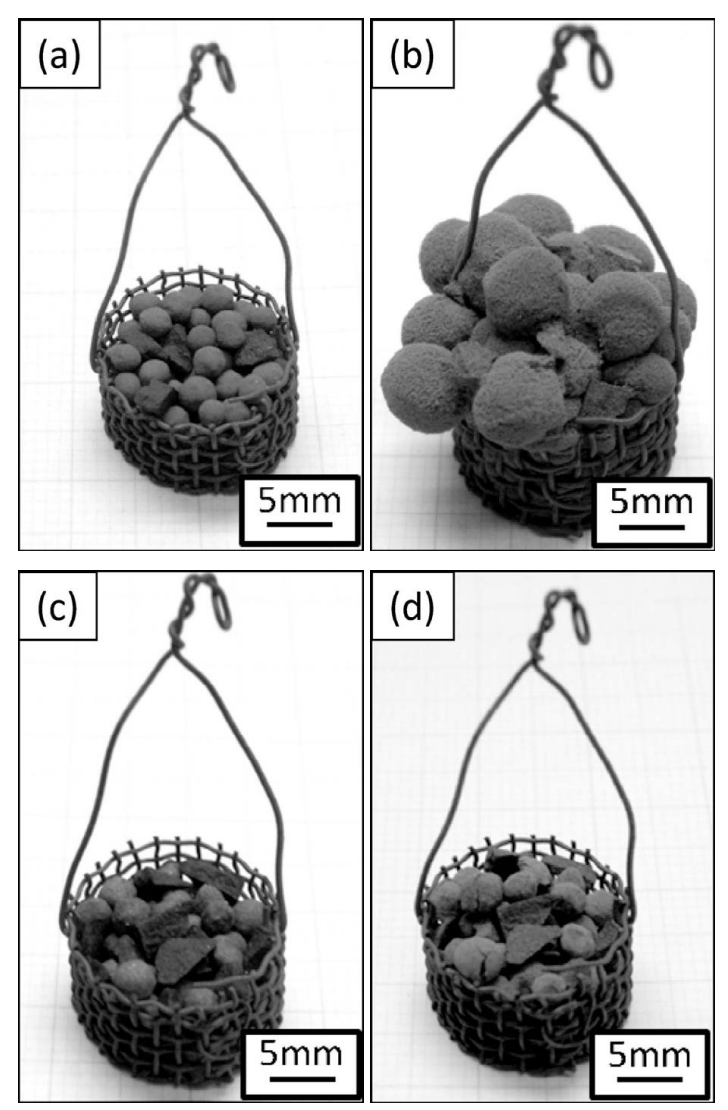

Fig. 11. Sample photographs from thermobalance test until $1050^{\circ} \mathrm{C}$ : (a) Pellet A-20\%B before test, (b) Pellet A- $20 \% \mathrm{~B}$ after test, (c) Pellet B-20\%B before test, (d) Pellet B$20 \% \mathrm{~B}$ after test.

Moreover, SEM images in the surfaces of pellets after tests are shown in Figs. 12(a) and 12(b). It is clear that fine fibrous irons having diameter $1-2 \mu \mathrm{m}$ are formed on pellet A. It proved that abnormal swelling of pellet A was caused by the formation of these fine fibrous irons entirely inside the pellet $\mathrm{A}$. In contrast, through a few fibrous irons were observed on pellet $\mathrm{B}$, these had a thicker diameter and formed only near the surface. As a result, remarkable swelling like pellet A did not occur on pellet B.

From previous researches by Hayashi et al., ${ }^{11-14)}$ it is supposed that these fibrous irons would be caused by gaseous sulfur derived from coal char in the briquettes. It is known that gaseous sulfur strongly chemisorbs on the reduced iron to enhance the vertical iron growth with inhibiting the lateral iron formation. ${ }^{11)}$ In addition, because it is reported that free $\mathrm{CaO}$ in the pellet promotes the formation of fibrous iron, the formation of fibrous irons could occur actively on pellet A. ${ }^{11-14)}$

From gasification behavior during $900^{\circ} \mathrm{C}-1050^{\circ} \mathrm{C}$ in Fig. 5 , a partial pressure ratio of gaseous $\mathrm{COS}$ against $\mathrm{CO} \mathrm{P}_{\mathrm{COS}} /$ $\mathrm{P}_{\mathrm{CO}}$ inside a packed bed can be estimated nearly $8.5 \times 10^{-5}$, which corresponded to the condition where maximum abnormal swelling takes place. ${ }^{11,13)}$

On the other hand, SEM image obtained in the surface of briquettes on pellet A-20\%B is shown in Fig. 12(c). A few thick fibrous irons was observed on the surface, not inside the briquettes, showing no swelling in mixed briquettes.

Based on the above results, it is undoubted that the active formation of a plenty of fine fibrous irons would cause the

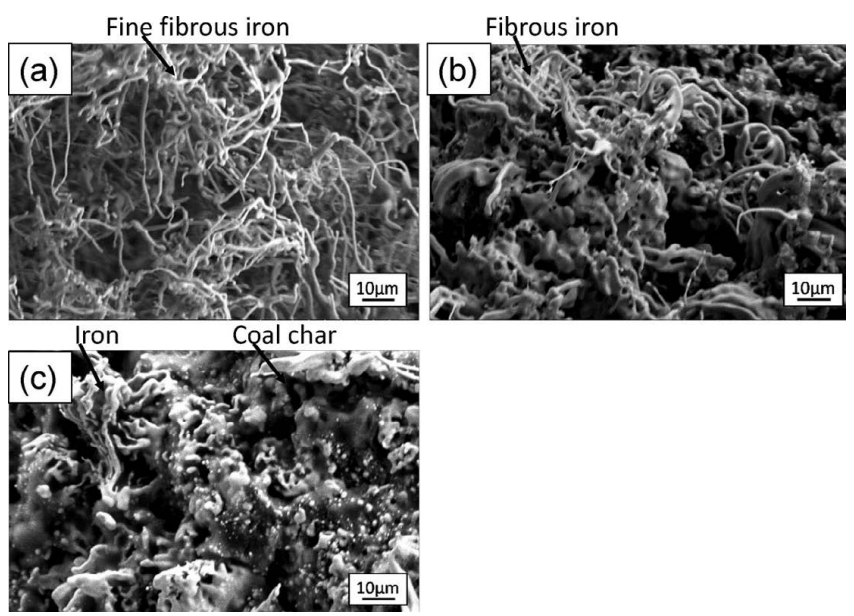

Fig. 12. SEM images in the surface of pellet or briquette after reaction (Pellet-20\%B bed, $1050^{\circ} \mathrm{C}$ ). (a) Pellet A, (b) Pellet B, (c) Briquette in Pellet A-20\%B.

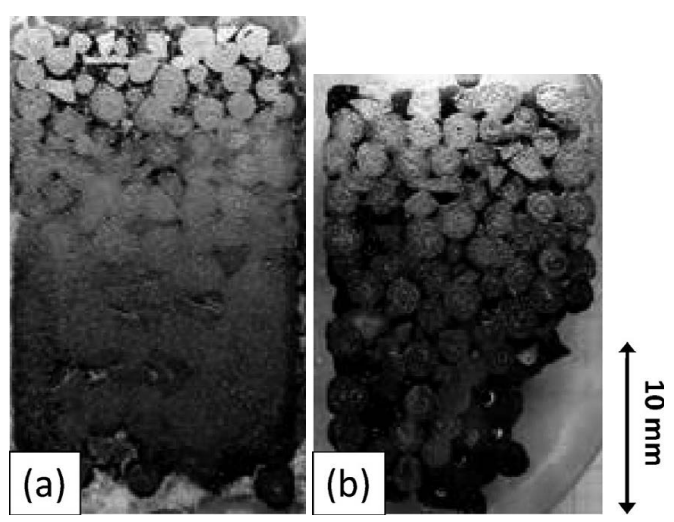

Fig. 13. Cross section of packed beds after reaction $\left(1050^{\circ} \mathrm{C}\right)$. (a) Pellet A-20\%B, (b) Pellet B-20\%B.

Table 4. Void fraction $\varepsilon$ estimated by using pressure drops in a packed bed at $1050^{\circ} \mathrm{C}$.

\begin{tabular}{cccc}
\hline Bed & $\Delta \mathrm{P}[\mathrm{kPa}]$ & $\Delta \mathrm{L}[\mathrm{cm}]$ & $\varepsilon$ \\
\hline Pellet A-20\%B & 29.19 & 2.72 & 0.184 \\
Pellet B-20\%B & 1.17 & 2.82 & 0.432 \\
\hline
\end{tabular}

blockade of inter spaces between pellets and briquettes, leading to great pressure drops on pellet $\mathrm{A}-20 \% \mathrm{~B}$ and $50 \% \mathrm{~B}$ beds.

Cross sections of packed beds for both pellets $-20 \% \mathrm{~B}$ $\left(1050^{\circ} \mathrm{C}\right)$ are shown in Fig. 13. On pellet A-20\%B, the inter spaces between pellets and briquettes is mostly blocked in the central parts of the packed bed compared with pellet B$20 \% \mathrm{~B}$.

Here, void fraction of the packed beds $\varepsilon$ was estimated by using Ergun's pressure drop equation ${ }^{15)}$ with the height of bed, gas flow condition and measured pressure drops at $1050^{\circ} \mathrm{C}$. As shown in Table 4, void fractions were calculated $18.4 \%$ on pellet $\mathrm{A}-20 \% \mathrm{~B}$ and $43.2 \%$ on pellet $\mathrm{B}-20 \% \mathrm{~B}$.

Microstructures in cross section of pellet in pellet A$20 \% \mathrm{~B}$ bed at $1050^{\circ} \mathrm{C}$ and $1200^{\circ} \mathrm{C}$ are shown in Fig. 14 . Fine iron grains which are considered cross section of fibrous irons are observed at $1050^{\circ} \mathrm{C}$, whereas iron grains coarsen at $1200^{\circ} \mathrm{C}$. These results imply that decrease of pressure drop would be caused by releasing blockade among 


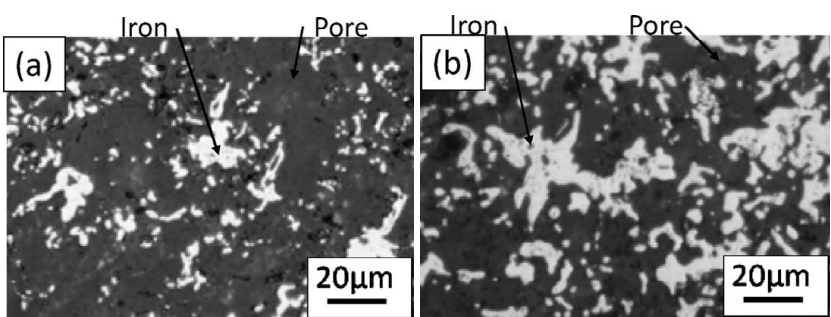

Fig. 14. Microstructures in cross section of pellet in pellet $A-20 \% B$ bed after reaction: (a) $1050^{\circ} \mathrm{C}$, (b) $1200^{\circ} \mathrm{C}$.

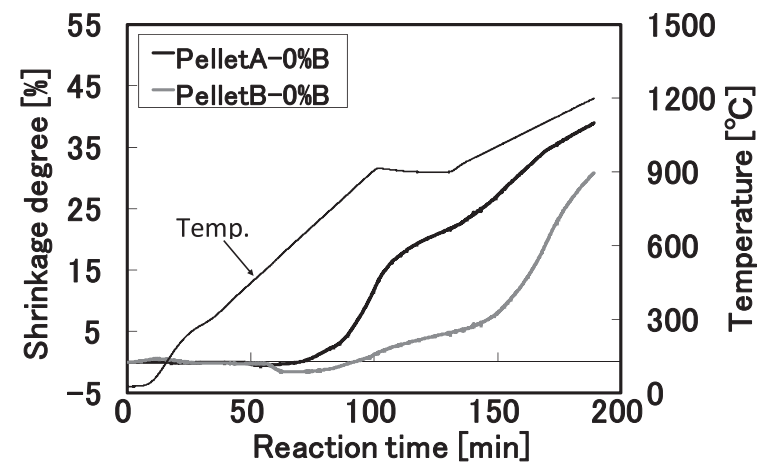

Fig. 15. Shrinkage degree with reaction time (Pellet only).

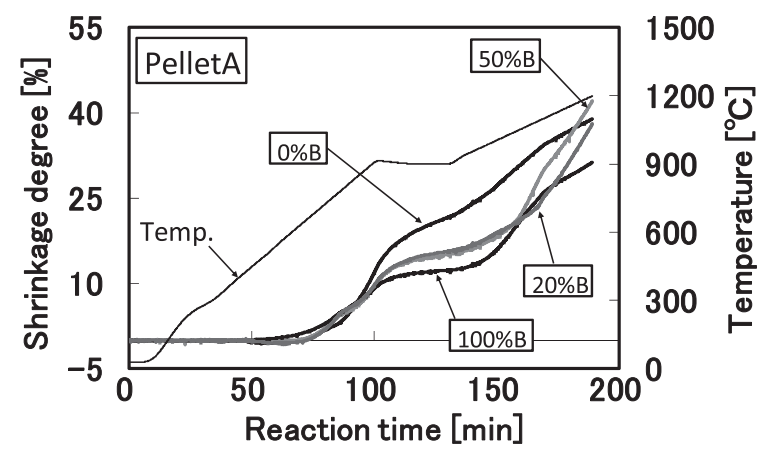

Fig. 16. Shrinkage degree of pellet A mixed bed with reaction time.

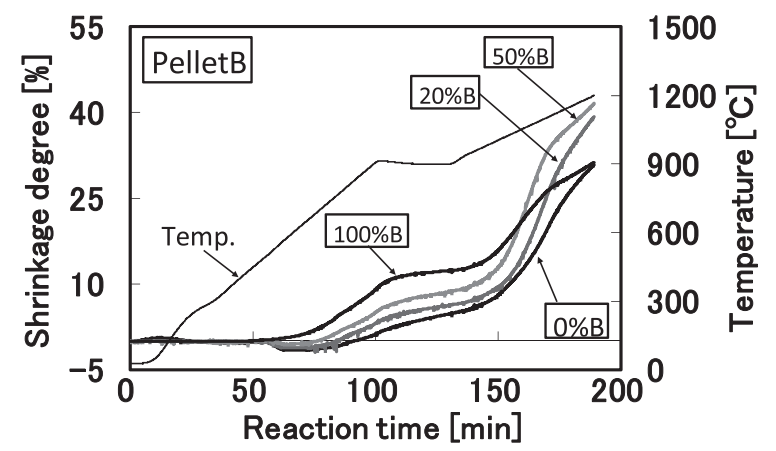

Fig. 17. Shrinkage degree of pellet $B$ mixed bed with reaction time.

their inter spaces due to sintering among fibrous irons.

\subsection{Shrinkage Degree}

Shrinkage degrees of packed beds on both pellets $-0 \% \mathrm{~B}$ with reaction time are shown in Fig. 15. It is found that shrinkage of pellet A is larger than pellet B during reaction.

Shrinkage degrees of mixed packed beds are shown in Figs. 16 and 17. Compared with pellet $\mathrm{A}-0 \% \mathrm{~B}$, on pellet A$20 \% \mathrm{~B}$ and $-50 \% \mathrm{~B}$, their shrinkage degrees are smaller from about $900^{\circ} \mathrm{C}$. This may be because of abnormal swelling of pellet A mentioned above.

On the other hand, on pellet $\mathrm{B}-20 \% \mathrm{~B}$ and $50 \% \mathrm{~B}$, their mixed beds are easy to shrink, because the coupling reactions between indirect reduction of pellets (Eq. (8)) and carbon solution loss reaction (Eq. (9)) in the briquettes would be activated, so that shrinkage degrees would be larger than on pellet $\mathrm{B}-0 \% \mathrm{~B}$.

On $1200^{\circ} \mathrm{C}$, the mixed beds provided larger final shrinkage of the beds than the individual beds for both pellets, probably due to increment of the coupling reactions mentioned above.

\subsection{Overall Discussion}

In this study, reaction behavior of a packed bed consisting of iron ore pellets and coal composite iron ore hot briquettes was examined under the blast furnace simulated conditions until $1200^{\circ} \mathrm{C}$.

Consequently, it was found that reducibility of the mixed packed bed is governed by reducibility of pellets, whereas gasification of briquettes in the packed bed is hardly governed by it.

However, promotion effects for reduction and gasification of the briquettes mixed beds were recognized for both pellets particularly around $1050^{\circ} \mathrm{C}$, where abnormal swelling of pellet A occurred remarkably with fine fibrous irons, showing a noticeable pressure drop through the bed.

It was assured that this swelling could be caused by gaseous sulfur derived from coal char in the briquettes from estimation of a gaseous sulfur pressure in the mixed bed referring to authors previous paper. ${ }^{11,13)}$

On the other hand, for pellet B thick fibrous irons were formed only on the surface, showing small swelling and not so high pressure drop through the bed. This would be because pellet $\mathrm{B}$ has few free $\mathrm{CaO}$ and suffers sufficient induration compared with pellet $\mathrm{A}$ indurated at $1100^{\circ} \mathrm{C}$. It is previously reported that sufficient induration of reagent hematite pellets suppresses considerably the abnormal swelling during reduction. ${ }^{12)}$

Regarding shrinkage of the bed, the mixed beds provided larger final shrinkage degree of the beds than the individual beds for both pellets, probably due to increment of the coupling reactions between reduction and gasification.

\section{Conclusions}

The influence of ore reducibility on blast furnace simulated reaction behavior of the packed ore bed mixed with coal composite iron ore hot briquette was investigated in the temperature ranges until $1200^{\circ} \mathrm{C}$. The following results were summarized.

(1) Reducibility of a mixed packed bed was governed by reducibility of pellets. In addition, the higher the mixing ratio of briquettes was, the faster the reduction of a packed bed was.

(2) Reduction promotion effect of a mixed packed bed was recognized on both pellets, samples including pellet A giving less than $5 \%$ in lower temperatures and both samples including $50 \% \mathrm{~B}$ giving nearly $10 \%$ around $1050^{\circ} \mathrm{C}$.

(3) Though gasification of a mixed packed bed was not almost governed by reducibility of pellets, gasification 
promotion effect of a mixed packed bed was recognized, samples including pellet B giving nearly $5 \%$ in lower temperatures and both samples including $20 \% \mathrm{~B}$ giving nearly $20 \%$ around $1050^{\circ} \mathrm{C}$.

(4) Reduction promotion of pellets by mixing briquettes was more observed in the upper part of the mixed bed.

(5) The formation of fine fibrous irons causes the blockade of the inter spaces between pellets and briquettes, leading to great pressure drops on pellet A mixed beds until about $1050^{\circ} \mathrm{C}$. Beyond then, the decrease of pressure drop would be caused by recovering the inter spaces formed by sintering among fibrous irons.

(6) Though some thick fibrous irons were confirmed on the surface of pellets in the mixed beds including pellet B, their pressure drops were not so high.

(7) On pellet A mixed beds, their shrinkage degrees of the beds were smaller beyond about $900^{\circ} \mathrm{C}$ compared with a pellet $\mathrm{A}$ bed, because of abnormal swelling of pellet $\mathrm{A}$.

(8) On pellet $\mathrm{B}$ mixed beds, their shrinkage degrees were larger than on a pellet B bed, because the coupling reactions between reduction of pellets and gasification in briquettes were activated.

\section{REFERENCES}

1) H. Sato, S. Machida, K. Nushiro, K. Ichikawa, M. Sato, T. Ariyama and K. Takeda: Tetsu-to-Hagané, 92 (2006), 815

2) S. Hayashi, N. Tomita and Y. Iguchi: Tetsu-to-Hagané, 90 (2004), 999.

3) M. Nakano, M. Naito, K. Higuchi and K. Morimoto: ISIJ Int., 44 (2004), 2079.

4) S. Nomura, H. Terashima, E. Sato and M. Naito: Tetsu-to-Hagané, 92 (2006), 849.

5) A. Kasai, M. Naito, Y. Matsui and Y. Yamagata: Tetsu-to-Hagané, 89 (2003), 1212.

6) A. Kasai and Y. Matsui: ISIJ Int., 44 (2004), 2073.

7) S. Hayashi, A. Inayoshi and H. Mizoguchi: CAMP-ISIJ, 22 (2009), 21, CD-ROM.

8) H. Mizoguchi, A. Inayoshi, K. Okumura and S. Hayashi: CAMP-ISIJ, 22 (2009), 93, CD-ROM.

9) H. Mizoguchi, H. Suzuki, K. Okumura and S. Hayashi: CAMP-ISIJ, 22 (2009), 769, CD-ROM

10) Y. Shimomura and T. Sugiyama: Private communication (1982).

11) S. Hayashi, Y. Iguchi and J. Hirao: Tetsu-to-Hagané, 71 (1985), 1311.

12) S. Hayashi and Y. Iguchi: Tetsu-to-Hagané, 73 (1987), 1668

13) S. Hayashi and Y. Iguchi: ISIJ Int., 43 (2003), 1370.

14) S. Hayashi and Y. Iguchi: Ironmaking Steelmaking, 32 (2005), 353.

15) Handbook of Iron and Steel, Ver. 4, ed. by ISIJ, Maruzen, Tokyo, (2002), CD-ROM. 